\title{
Effects of parity on uterine involution and resumption of ovarian activities in postpartum Chinese Holstein dairy cows
}

\author{
J. Zhang, ${ }^{*}$ L. X. Deng,† H. L. Zhang, ${ }^{*}$ G. H. Hua, ${ }^{*}$ L. Han, ${ }^{*}$ Y. Zhu,‡ X. J. Meng,‡ and L. G. Yang ${ }^{* 1}$ \\ ${ }^{*}$ Key Laboratory of Agricultural Animal Genetics, Breeding and Reproduction, Ministry of Education, Huazhong Agricultural University, Wuhan, \\ 430070, China \\ †College of Animal Husbandry \& Veterinary Science, Henan Agricultural University, Zhengzhou, 450002, China \\ ‡Dingyuan Breeding Centre, Zhengzhou, 450008, China
}

\begin{abstract}
Favorable uterine involution and ovarian activity are very important for the next reproductive cycle of postpartum cows. The objective of this study was to evaluate the effect of parity on uterine involution and resumption of ovarian activity in Chinese Holstein dairy cows after calving under similar postpartum nutritional conditions. Traits of the status of uterus and ovaries detected by ultrasonography, dry matter intake (DMI), milk yield, body condition score (BCS), and estradiol concentration in milk samples were analyzed for 46 Chinese Holstein dairy cows in various parities (primiparous $=18 ;$ biparous $=13 ;$ multiparous $=15)$. The results showed that there was no significant difference for DMI, BCS, and milk yield among different parities; all cows were considered to be under similar nutritional conditions. Days of the previous gravid uterine horn involution were significantly greater in primiparous dairy cows than in biparous and multiparous dairy cows. Days from calving to ovulation (first and second) and the number of follicular waves to first ovulation were significantly greater in primiparous cows than in multiparous cows. In summary, there was a significant negative relationship between parity and postpartum uterine involution and resumption of ovarian activity in Chinese Holstein cows under similar body conditions.
\end{abstract}

Key words: parity, Chinese Holstein cow, uterine involution, ovarian activity

\section{INTRODUCTION}

Uterine involution and ovarian resumption of cows after calving are very important to ensure the next reproductive cycle. Prolonging the open period after parturition will lead to huge economic losses for farmers. Body nutritional status is one of the main factors

Received August 8, 2009.

Accepted January 11, 2010.

${ }^{1}$ Corresponding author: yangliguo2006@yahoo.com.cn that affect the reproductive performance of cows during the postpartum period (Beam and Butler, 1999; Butler, 2000, 2003). However, the effect of parity on uterus involution and ovarian resumption in cows kept under similar nutritional conditions is still controversial. In a study by Rekwot et al. (2000) on the uterine involution of Zebu (Bos indicus) cows, resumption of ovarian activity was earlier in cows with 3 to 5 calvings than in those with 1 to 2 calvings. Tanaka et al. (2008) also demonstrated a negative relationship between parity and the number of days from calving to first ovulation in dairy cows under similar body nutritional conditions. However, Miettinen (1990) thought that the parity of Finnish dairy cows had no significant effect on the swiftness of uterine or cervical involution. Darwash et al. (1997) reported that the interval from calving to postpartum ovulation became progressively longer as the number of parity increased in British Friesian cows. It was supposed that the relationship between parity and resumption of reproductive function may vary among breeds or lines of cows. The Chinese Holstein cow is a famous, milk-purpose, domestic breed in China that was cultivated from the imported Holstein by continuing crossbreeding with Chinese local cattle. The objective of the present study was to evaluate the relationship between parity and the resumption of activity of reproductive organs (uterus and ovaries) in Chinese Holstein cows under similar nutritional conditions after calving.

\section{MATERIALS AND METHODS}

\section{Animals}

In the present study, a total of 46 Chinese Holstein dairy cows were divided into 3 groups: primiparous (n $=18)$, biparous $(\mathrm{n}=13)$, and multiparous $[\mathrm{n}=15$; parity: third $(\mathrm{n}=9)$, fourth $(\mathrm{n}=4)$, and sixth $(\mathrm{n}=$ $2)]$. All the experimental animals were raised on the dairy farm of Ding Yuan Breeding Centre in Henan Province of China. The mean BCS levels of all cows at the start of the experiment were limited to 3 to 3.5 
(on a scale from 1 to 5 , where $1=$ extremely thin and $5=$ extremely fat). During the experiment, TMR was used to meet or exceed the predicted nutrition requirements (NRC, 2001). All cows were offered diet for ad libitum intake. Before the experiment began, the cows were confirmed to be free of clinical uterine infection, periparturient diseases, calving difficulty, and other general reproductive problems.

\section{BCS, Milk Yield, and DMI Measurement}

Body condition score was measured every other week, starting at $7 \mathrm{~d}$ after calving, and assessed by the BCS flowchart (Ferguson et al., 1994). Milk yield of the individuals was recorded daily by an automatic monitoring system at the milking parlor. Daily DMI was calculated and recorded.

\section{Ultrasonographic Observation}

Transrectal ultrasonography of the uterus and ovaries was undertaken with a B-mode veterinary ultrasound scanner (Shenzhen Well.D Medical Electronics Co. Ltd., Guangdong, China) equipped with a 7.5- or 5.0$\mathrm{MHz}$ linear array transducer (Okano and Tomizuka, 1987; Kamimura et al., 1993; Sheldon and Dobson, 2000; Kohan-Ghadr et al., 2008). Photographs of the uterus and ovaries were transmitted to a computer workstation and analyzed to assess the extent of uterine involution and ovarian follicle activity on different postpartum days.

Uterine ultrasonographic observations starting at 7 $\mathrm{d}$ after calving were performed every $3 \mathrm{~d}$ up to full involution. Diameters of uterine cervix and horn (gravid) were measured by ultrasonography. The uterus was considered fully involuted when the cervix and previous gravid horn diameter after calving decreased to unchanged and were similar to that of nongravid uterus.

Ovarian ultrasonographic observations starting at $7 \mathrm{~d}$ after calving were performed every other day and then daily after the confirmation of clinical signs of estrus, up to the second ovulation. Ultrasonographic images of the ovaries were collected to analyze follicular waves, dominant ovarian follicle development, and ovulation. The size of follicles that grew to greater than $8 \mathrm{~mm}$ in diameter was recorded. For the analysis of follicles, the mean values of the long and short diameters on the images were recorded as the follicular diameter.

\section{Milk Estradiol Concentration Assay}

Milk samples $(20 \mathrm{~mL})$ were collected at the same time that ovarian ultrasonographic observations were done. Samples were collected from all nipples and taken back to the laboratory in an icebox. Samples were centrifuged at $2,700 \times g$ for $10 \mathrm{~min}$ at $4^{\circ} \mathrm{C}$, and milk serum was harvested and stored at $-20^{\circ} \mathrm{C}$ until assayed for estradiol.

The concentrations of estradiol were measured by RIA (Medan et al., 2004; Sheldon et al., 2004). Estradiol in skim milk was analyzed with an estradiol RIA kit (Beijing Chemclin Biotech Co. Ltd, Beijing, China). The intra- and interassay coefficients of variation for estradiol were less than 15 and $10 \%$, respectively. The sensitivities for the estradiol assays were less than 3 $\mathrm{pg} / \mathrm{mL}$.

\section{Statistical Analysis}

All data were presented as means \pm standard deviation. Traits of BCS, milk yield, DMI, diameters of uterine cervix and gravid uterine horn, days of uterine (cervix and gravid horn) involution, follicular waves, days of first and second ovulation, intervals between 2 ovulations, milk estradiol concentration, and maximum diameters of ovulatory follicle were calculated by the one-way ANOVA program of SPSS (version 13.0, SPSS Inc., Chicago, IL). A probability of $P<0.05$ was considered statistically significant.

\section{RESULTS}

\section{BCS, DMI, and Milk Yield}

In the present study, the BCS of cows were all more than 2.5 during the postpartum period. There was no significant difference in BCS among primiparous, biparous, and multiparous Chinese Holstein cows throughout the experiment (Figure 1). The weekly mean values of milk yield and DMI (from parturition to $77 \mathrm{~d}$ postpartum) of the primiparous, biparous, and multiparous groups is presented in Figure 1; the difference among the 3 groups was not significant.

\section{Uterine Cervix and Gravid Uterine Horn}

No significant difference was found in the uterine cervix involution of the 3 groups (Table 1) or in the changes in uterine cervix diameter (Figure 2). However, as the postpartum interval increased, diameters of the previous gravid horn of biparous and multiparous cows decreased more quickly than those of primiparous cows (Figure 3). Interval (days) from calving to the involution of the previous gravid uterine horn in primiparous cows was significantly longer than that in biparous and multiparous cows $(P<0.01$; Table 1$)$. No significant difference was found between biparous and multiparous cows (Table 1). 

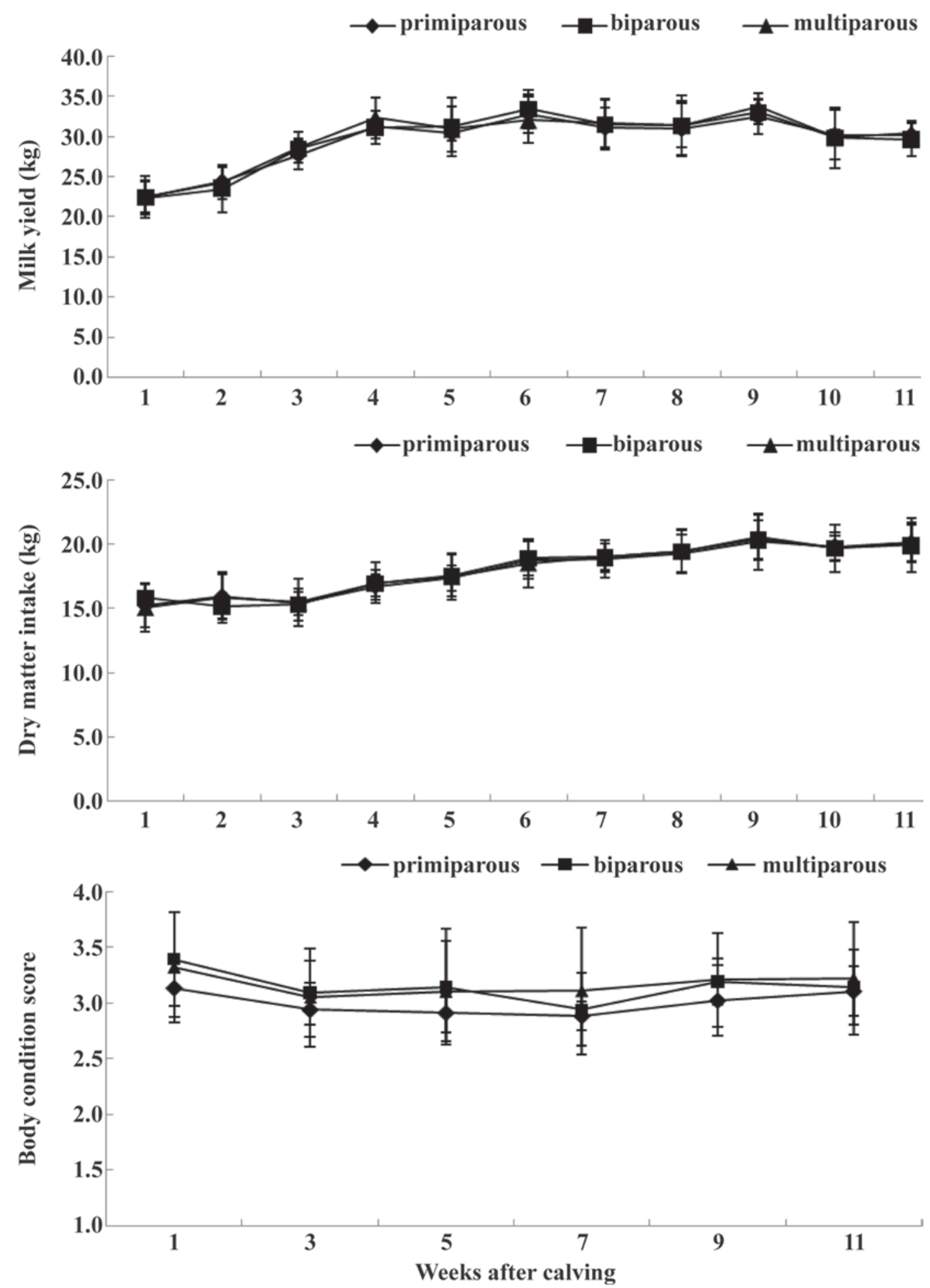

Figure 1. Changes in milk yield, DMI, and BCS among primiparous, biparous, and multiparous Chinese Holstein cows after calving. There was no significant difference for changes of milk yield and DMI among the 3 groups during the whole test period. The BCS levels of all cows were $>2.5$, and the difference was not obvious for the BCS value among the 3 groups throughout the experiment. 


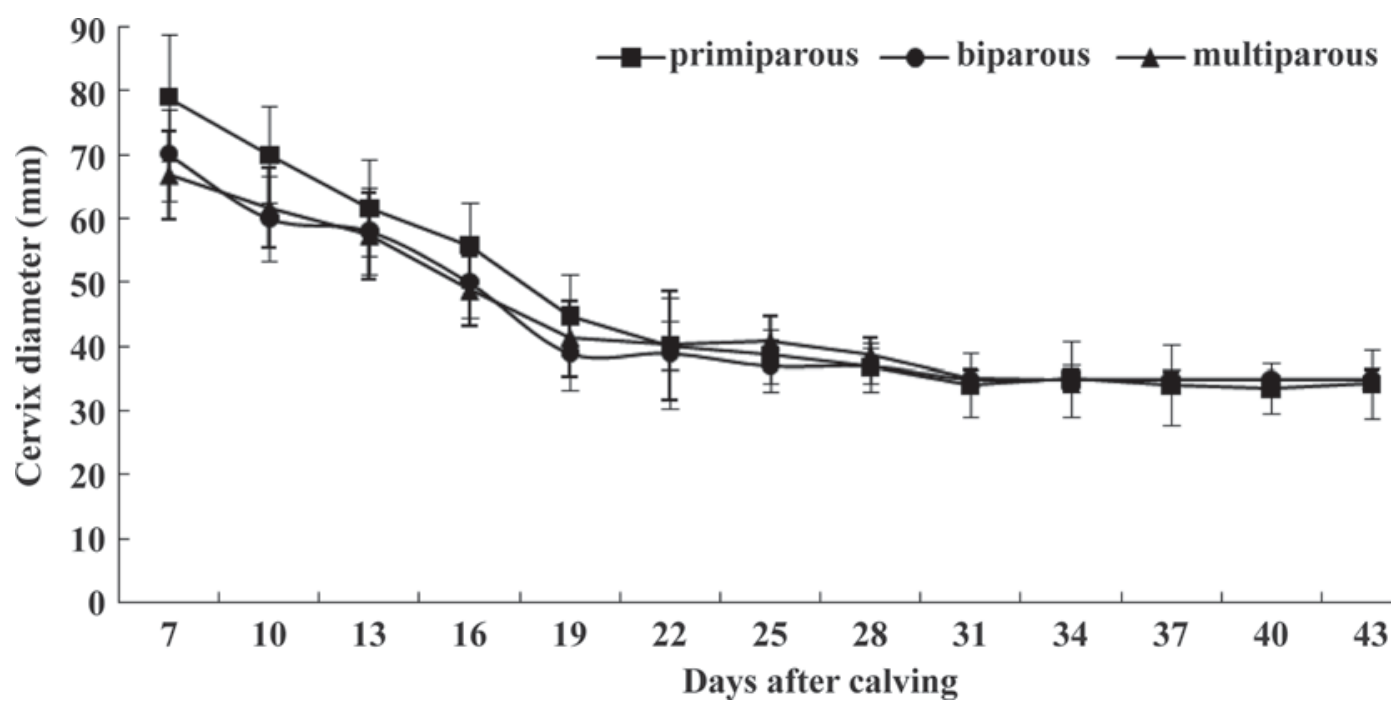

Figure 2. Changes of uterine cervix diameters among primiparous, biparous, and multiparous Chinese Holstein cows after calving. There was no significant difference for changes in uterine cervix diameters among the 3 groups.

\section{Follicular Waves Before Ovulation}

In 3 groups, the diameters of dominant follicles more than $8 \mathrm{~mm}$ were recorded by type B ultrasonic from 7 $\mathrm{d}$ after calving. The first ovulation of most test cows usually accorded with the 3 representative patterns (Beam and Butler, 1997; Tanaka et al., 2008): 1) the first detected dominant follicle grew and then ovulated (Figure 4a); 2) the first detected dominant follicle grew but then shrank back, and a new dominant follicle (the second dominant wave) grew and ovulated (Figure 4b); or 3) the first and second dominant follicles did not ovulate and a new dominant follicle of the third follicular wave grew and ovulated (Figure 4c). The number of cows exhibiting ovulation after the first, second, and third follicular wave, respectively, was as follows: 2, 5, and 9 for primiparous cows; 4, 4, and 3 for biparous cows; and 5, 7, and 3 for multiparous cows. In the cows that ovulated during the first follicular wave, the number of biparous $(\mathrm{n}=4)$ and multiparous $(\mathrm{n}=5)$ cows was greater than the number of primiparous cows $(\mathrm{n}=2)$. In the cows that ovulated during the second follicular wave, the number of multiparous cows $(\mathrm{n}=$ 7 ) was greater than the number of primiparous $(\mathrm{n}=5)$ and biparous $(\mathrm{n}=4)$ cows. In the cows that ovulated during the third follicular wave, the number of biparous $(\mathrm{n}=3)$ and multiparous $(\mathrm{n}=3)$ cows was less than the number of primiparous cows $(\mathrm{n}=9)$.

Two other patterns were also observed (Figures 4d and 4e) and are characterized as follows: 1) the first, second, and third dominant follicles did not ovulate and a new dominant follicle of the forth follicular wave grew and ovulated (observed in 1 primiparous cow and 2 biparous cows; Figure 4d); and 2) the first, second, third, and fourth waves did not ovulate and a new dominant follicle of the fifth follicular wave grew and ovulated (observed in 1 primiparous cow; Figure 4e).

The number of follicular waves of primiparous cows to first ovulation was significantly more than that of multiparous cows $(P<0.05$, Table 2$)$.

\section{First and Second Ovulation, Ovulatory Interval, and Ovulatory Follicle Diameter}

There was a significant negative relationship between parity and days from calving to ovulation (Table 2). Days of first and second ovulation after calving were significantly greater in primiparous cows than in mul-

Table 1. Interval (mean \pm SD) from calving to the involution of uterine cervix and horns in different parities of Chinese Holstein cows

\begin{tabular}{lccc}
\hline Parity & Cows $(\mathrm{n})$ & $\begin{array}{c}\text { Interval from calving to uterine } \\
\text { cervix involution }(\mathrm{d})\end{array}$ & $\begin{array}{c}\text { Interval from calving to gravid } \\
\text { uterine horn involution }(\mathrm{d})\end{array}$ \\
\hline Primiparous & 18 & $31.7 \pm 4.2$ & $35.3 \pm 4.6^{\mathrm{a}}$ \\
Biparous & 13 & $32.7 \pm 3.5$ & $23.7 \pm 5.0^{\mathrm{b}}$ \\
Multiparous & 15 & $29.1 \pm 5.2$ & $22.7 \pm 4.5^{\mathrm{b}}$ \\
\hline
\end{tabular}

${ }^{\mathrm{a}, \mathrm{b}}$ Values with different superscripts differ $(P<0.01)$. 


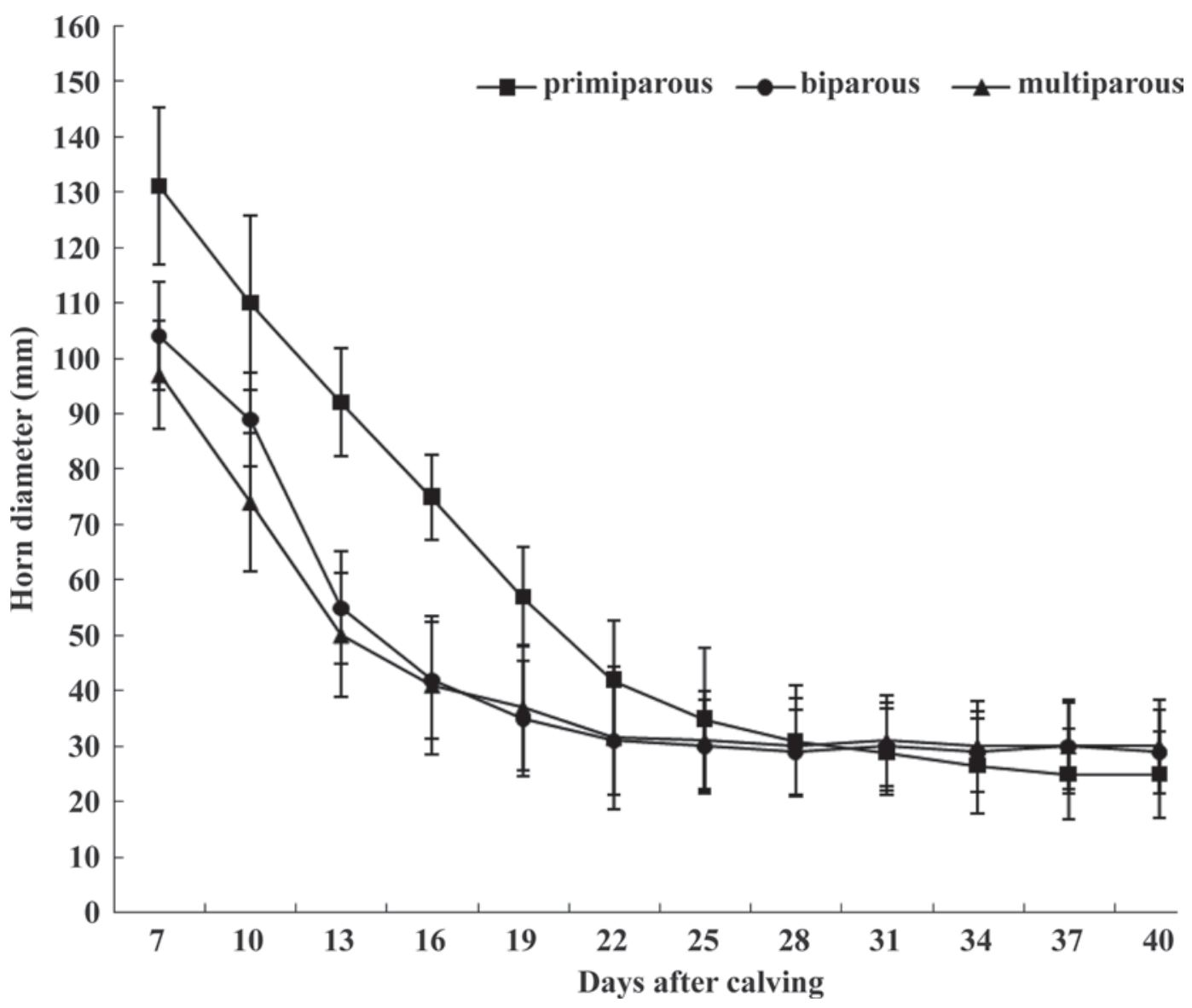

Figure 3. Changes in uterine horn (gravid) diameters among primiparous, biparous, and multiparous Chinese Holstein cows after calving. Previous gravid horn diameters of biparous and multiparous cows decreased more quickly than those of primiparous cows as postpartum days increased. The difference was not obvious between biparous and multiparous cows.

tiparous cows $(P<0.05 ;$ Table 2$)$. The intervals from first to second ovulation and the maximum diameters of ovulatory follicles did not differ significantly among primiparous, biparous, and multiparous cows (Table 2).

\section{Estradiol Secretion}

Among all primiparous, biparous, and multiparous cows after calving, the concentrations of estradiol decreased and remained close to the baseline. Estradiol concentrations increased in parallel with the growth of the ovulatory follicle (Figure 4). However, a sharp peak of estradiol was found before ovulation. It was shown that the maximum peak values of estradiol concentrations before first ovulation increased with parity, but the difference among the 3 groups was not obvious (Table 2).

\section{DISCUSSION}

In the present study, the difference of BCS was slight among primiparous, biparous, and multiparous Chinese
Holstein cows and BCS in all groups was maintained at a level of more than 2.5 throughout the experiment. Moreover, milk yield and DMI did not differ significantly among the 3 groups. The results suggested that all cows maintained good body condition levels during the postpartum period. Under such body nutritional conditions, the results revealed that involution of reproductive function (uterus and ovaries) after parturition differed significantly among primiparous, biparous, and multiparous cows.

Previous reports are inconsistent regarding the effect of parity on uterine involution in different breeds of cattle. Some researchers consider that parity has no significant effect on uterine involution (Miettinen, 1990; Nogueira et al., 1993; Baruselli et al., 1996), whereas other researchers suggest that the time of uterine involution increases with parity (Zain et al., 1995; Gonzalez Sanchez et al., 1999; Hajurka et al., 2005). It is well known that many factors affect uterine involution, including breed, nutrition, parity, uterine diseases, and environment. In this study, other factors were kept in the same state and only the effect of parity 

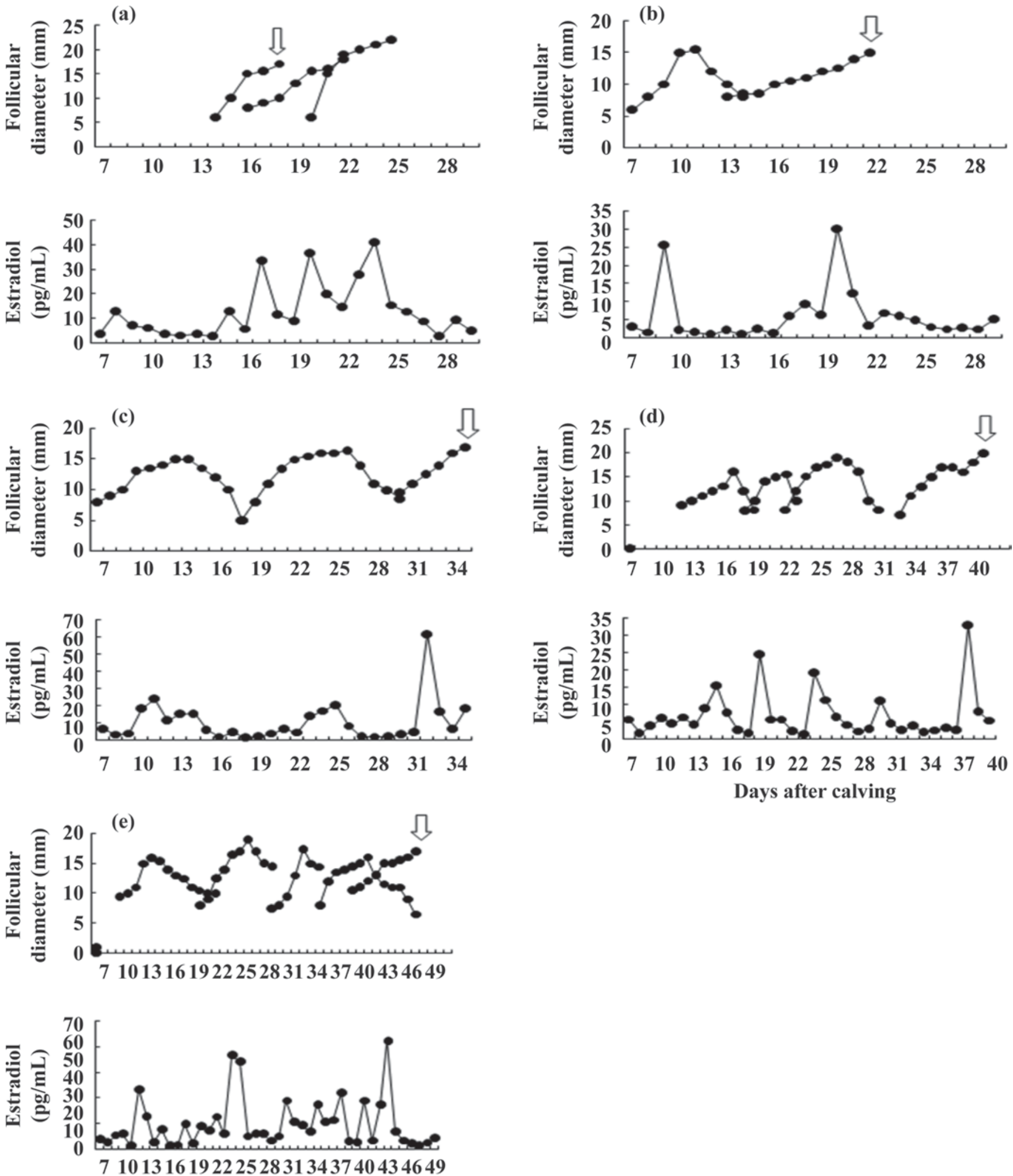

Days after calving

Figure 4. Several changes of follicular waves and relative estradiol concentrations in cows with different parities from calving to first ovulation. Figures a, b, and c show 3 typical patterns of ovulation after calving, but figures d and e show patterns that are first reported in this study. Arrows represent the first ovulation.

Journal of Dairy Science Vol. 93 No. 5, 2010 
Table 2. The characteristic of the first and second follicle ovulation and hormonal profiles after calving among primiparous, biparous, and multiparous Chinese Holstein cows (mean $\pm \mathrm{SD}$ )

\begin{tabular}{lcccccc}
\hline & $\begin{array}{c}\text { First ovulation } \\
(\mathrm{d})\end{array}$ & $\begin{array}{c}\text { Second } \\
\text { ovulation (d) }\end{array}$ & $\begin{array}{c}\text { Interval between } \\
\text { first and second } \\
\text { ovulations (d) }\end{array}$ & $\begin{array}{c}\text { Maximum diameter of } \\
\text { ovulatory follicle (mm) }\end{array}$ & $\begin{array}{c}\text { Follicular waves to } \\
\text { first ovulation (n) }\end{array}$ & $\begin{array}{c}\text { Maximum peak value } \\
\text { of estradiol before first } \\
\text { ovulation (pg/mL) }\end{array}$ \\
\hline Primiparous & $31.8 \pm 10.1^{\mathrm{a}}$ & $57.6 \pm 16.2^{\mathrm{a}}$ & $25.7 \pm 11.7$ & $17.1 \pm 2.0$ & $2.7 \pm 1.0^{\mathrm{a}}$ & $38.0 \pm 7.2$ \\
Biparous & $25.7 \pm 8.2$ & $45.7 \pm 10.8$ & $20.0 \pm 2.6$ & $16.3 \pm 1.5$ & $2.2 \pm 1.1$ & $40.8 \pm 9.5$ \\
Multiparous & $21.3 \pm 5.0^{\mathrm{b}}$ & $43.5 \pm 5.3^{\mathrm{b}}$ & $22.3 \pm 6.3$ & $16.5 \pm 1.6$ & $1.9 \pm 0.7^{\mathrm{b}}$ & $42.8 \pm 10.4$ \\
\hline
\end{tabular}

${ }^{\mathrm{a}, \mathrm{b}}$ Values within the same column with different superscripts differ $(P<0.05)$.

was evaluated. Uterine involution was reflected by the postpartum resumption of the cervix and gravid horn. The pattern of decreasing diameter of uterine cervix with increasing time after parturition among different parities was similar. However, intervals of previous gravid uterine horn involution were significantly greater in primiparous cows than in biparous and multiparous cows. The results clearly show that the effect of parity on uterine involution indeed exists and that previous gravid horn involution after calving shortens as the number of parity increases.

Several patterns of follicular development after parturition have been reported previously. Cows that ovulated after the first or second follicular wave were biparous and multiparous cows, but primiparous cows were more likely to ovulate after the second or third follicular wave. Two more patterns of follicular development were first recorded here. The number of follicular waves to first ovulation was apparently higher in primiparous cows than in multiparous cows. These results also suggested that the longer interval from calving to first ovulation in primiparous cows than in multiparous cows was caused by repetitious follicular waves of nonovulatory follicles, as reported previously (Tanaka et al., 2008).

The onset of ovulation after calving represents the resumption of ovarian activity. The effects of parity on the resumption of ovarian activity are various in different studies. Similar studies have revealed that ovulation is affected by parity (Dimmick et al., 1991; Tanaka et al., 2008; Balogh et al., 2009), whereas some researchers argue that post-calving ovarian activity is not affected by parity (Zain et al., 1995) or that the interval from calving to ovulation grows longer as parity increases (Darwash et al., 1997). In the present study, days of first and second ovulation after calving in cows with different parities were considered. Results suggest that parity is negatively associated with ovulation (first and second) after calving, as prior studies showed (Rekwot et al., 2000; Tanaka et al., 2008; Balogh et al., 2009). In this experiment, an increase in estradiol concentration was observed during the process of growth of the dominant follicles in all cows. A sharp peak of estra- diol concentration was found before ovulation, and the mean peak values of estradiol concentrations in cows increased with parity. This result was not similar with that of a former report (Grimard et al., 1995), the result of which was that lower estradiol concentrations in primiparous cows than in multiparous cows might bring about more follicular waves and longer delayed ovulation.

\section{CONCLUSIONS}

The present study demonstrated that the influence of parity on the resumption of uterine and follicular activity was significant among primiparous, biparous, and multiparous Chinese Holstein cows of similar good body condition. Multiparous cows after calving completed gravid uterine horn involution earlier than did primiparous cows. Intervals of the first and second ovulations after calving were greater in primiparous cows than in multiparous cows.

\section{ACKNOWLEDGMENTS}

This work was supported by the National High Technology Research and Development Program of China (NHTRDPC-863 Project; No. 2008AA101010) and the earmarked fund for Modern Agroindustry Technology Research System (MATRS; No. nycytx-10).

\section{REFERENCES}

Balogh, O., K. Kovács, M. Kulcsár, A. Gáspárdy, A. Zsolnai, L. Kátai, A. Pécsi, L. Fésüs, W. R. Butler, and G. Huszenicza. 2009. AluI polymorphism of the bovine growth hormone (GH) gene, resumption of ovarian cyclicity, milk production and loss of body condition at the onset of lactation in dairy cows. Theriogenology 71:553-559.

Baruselli, P. S., R. G. Mucciolo, W. G. Vaina, F. G. Castro Jr., E. H. de Reichert, and R. H. Alvarez. 1996. Postpartum uterine involution in buffalo cows (Bubalus bubalis). Boletim de Indústria Animal 53:51-56.

Beam, S. W., and W. R. Butler. 1997. Energy balance and ovarian follicle development prior to the first ovulation postpartum in dairy cows receiving three levels of dietary fat. Biol. Reprod. $56: 132-142$. 
Beam, S. W., and W. R. Butler. 1999. Effects of energy balance on follicular development and first ovulation in postpartum dairy cows. J. Reprod. Fertil. Suppl. 54:411-424.

Butler, W. R. 2000. Nutritional interactions with reproductive performance in dairy cattle. Anim. Reprod. Sci. 60-61:449-457.

Butler, W. R. 2003. Energy balance relationships with follicular development, ovulation and fertility in postpartum dairy cows. Livest. Prod. Sci. 83:211-221.

Darwash, A. O., G. E. Lamming, and J. A. Woolliams. 1997. Estimation of genetic variation in the interval from calving to postpartum ovulation of dairy cows. J. Dairy Sci. 80:1227-1234.

Dimmick, M. A., T. Gimenez, and J. C. Spitzer. 1991. Ovarian endocrine activity and development of ovarian follicles during the postpartum interval in beef cows. Anim. Reprod. Sci. 24:173183.

Ferguson, J. D., D. T. Galligan, and N. Thomsen. 1994. Principal descriptors of body condition score in Holstein cows. J. Dairy Sci. 77:2695-2703.

Gonzalez Sanchez, J. P., E. Bianchini Sobrinho, and A. A. M. Goncalves. 1999. Uterine involution in dairy Gir cows, according to postpartum period and parity. Arq. Bras. Med. Vet. Zoo. $51: 345-351$.

Grimard, B., P. Humblot, A. A. Ponter, J. P. Mialot, D. Sauvant, and M. Thibier. 1995. Influence of postpartum energy restriction on energy status, plasma LH and oestradiol secretion and follicular development in suckled beef cows. J. Reprod. Fertil. 104:173179

Hajurka, J., V. Macak, and V. Hura. 2005. Influence of health status of reproductive organs on uterine involution in dairy cows. Bull. Vet. Inst. Pulawy 49:53-58.

Kamimura, S., T. Ohgi, M. Takahashi, and T. Tsukamoto. 1993. Postpartum resumption of ovarian activity and uterine involution monitored by ultrasonography in Holstein cows. J. Vet. Med. Sci. 55:643-647.

Kohan-Ghadr, H. R., R. C. Lefebvre, G. Fecteau, L. C. Smith, B. D. Murphy, J. Suzuki Junior, C. Girard, and P. Hélie. 2008.
Ultrasonographic and histological characterization of the placenta of somatic nuclear transfer-derived pregnancies in dairy cattle. Theriogenology 69:218-230.

Medan, M. S., G. Watanabe, K. Sasaki, and K. Taya. 2004. Transrectal ultrasonic diagnosis of ovarian follicular cysts in goats and treatment with GnRH. Domest. Anim. Endocrinol. 27:115-124.

Miettinen, P. V. 1990. Uterine involution in Finnish dairy cows. Acta Vet. Scand. 31:181-185.

NRC. 2001. Nutrient Requirements of Dairy Cattle. 7th rev. ed. Natl. Acad. Sci., Washington, DC.

Nogueira, L. A. G., L. E. L. Pinheiro, A. L. Norte, and V. J. Andrade. 1993. Uterine involution and return to cycling ovarian activity in zebu cows. Revista Brasileira de Reproducao Animal 17:49-56.

Okano, A., and T. Tomizuka. 1987. Ultrasonic observation of postpartum uterine involution in the cow. Theriogenology 27:369-376.

Rekwot, P. I., D. Ogwu, and E. O. Oyedipe. 2000. Influence of bull biostimulation, season and parity on resumption of ovarian activity of zebu (Bos indicus) cattle following parturition. Anim. Reprod. Sci. 63:1-11.

Sheldon, I. M., and H. Dobson. 2000. Effect of administration of eCG to postpartum cows on folliculogenesis in the ovary ipsilateral to the previously gravid uterine horn and uterine involution. J. Reprod. Fertil. 119:157-163.

Sheldon, I. M., D. E. Noakes, A. N. Rycroft, and H. Dobson. 2004 Effect of intrauterine administration of oestradiol on postpartum uterine bacterial infection in cattle. Anim. Reprod. Sci. 81:1323.

Tanaka, T., M. Arai, S. Ohtani, S. Uemura, T. Kuroiwa, S. Kim, and H. Kamomae. 2008. Influence of parity on follicular dynamics and resumption of ovarian cycle in postpartum dairy cows. Anim. Reprod. Sci. 108:134-143.

Zain, A. E., T. Nakao, M. A. Raouf, M. Moriyoshi, K. Kawata, and Y. Moritsu. 1995. Factors in the resumption of ovarian activity and uterine involution in postpartum dairy cows. Anim. Reprod. Sci. 38:203-214. 